\title{
Hydrogen Peroxide-mediated Toxicity for Leishmania donovani chagasi Promastigotes \\ Role of Hydroxyl Radical and Protection by Heat Shock
}

\author{
Jonathan H. Zarley, Bradley E. Britigan, and Mary E. Wilson \\ Veterans Administration Medical Center and Department of Internal Medicine, \\ University of Iowa College of Medicine, Iowa City, Iowa 52242
}

\begin{abstract}
Leishmania must survive despite exposure to the toxic oxidant hydrogen peroxide $\left(\mathrm{H}_{2} \mathrm{O}_{2}\right)$ during phagocytosis by macrophages. We investigated the mechanism of $\mathrm{H}_{2} \mathrm{O}_{2}$ toxicity for $L$. donovani chagasi promastigotes, and factors responsible for their relative $\mathrm{H}_{2} \mathrm{O}_{2}$ resistance. There was a dose-dependent toxic effect of $\mathrm{H}_{2} \mathrm{O}_{2}$ for promastigotes isolated during logarithmic phase of growth. In contrast, stationary phase promastigotes were less susceptible to $\mathrm{H}_{2} \mathrm{O}_{2}$ toxicity, and more infectious for BALB/c mice. By spin trapping we found that hydroxyl radical $(\cdot \mathrm{OH})$ was generated after exposure of promastigotes to $\mathrm{H}_{2} \mathrm{O}_{2}$, and the amount of $\cdot \mathrm{OH}$ was greater with log-phase than with stationary-phase promastigotes. - $\mathrm{OH}$ was generated after the addition of $\mathrm{H}_{2} \mathrm{O}_{2}$ to the cytosol but not the membranes of fractionated promastigotes, and the magnitude of $\cdot$ OH was greater in log than in stationary promastigote cytosol. Deferoxamine inhibition suggested that intracellular promastigote iron catalyzes $\cdot \mathrm{OH}$ formation via the Fenton reaction. Furthermore, exposure of log-phase promastigotes to heat shock induced a relative $\mathrm{H}_{2} \mathrm{O}_{2}$-resistant state, which was not associated with a decrease in $\cdot \mathrm{OH}$ formation but which required ongoing transcription. Thus, growth to stationary phase and heat shock both induce a state of relative $\mathrm{H}_{2} \mathrm{O}_{2}$ resistance, but these are probably due to different resistance mechanisms. (J. Clin. Invest. 1991. 88:1511-1521.) Key words: macrophage $\bullet$ intracellular parasite $\bullet$ electron paramagnetic resonance spectrometry (EPR) • virulence factors • spin trapping
\end{abstract}

\section{Introduction}

Leishmania donovani are obligate intracellular parasites of mammalian macrophages that cause the potentially fatal disease, visceral leishmaniasis. Like other Leishmania sp., strains of $L$. donovani exist in two morphologic forms. The extracellular promastigote stage is introduced into subcutaneous tissue in

This work was presented in abstract form at the American Federation for Clinical Research meeting, May 1990, Washington, DC (1990. Clin. Res. 38:305A).

Dr. Zarley's current address is Department of Internal Medicine, University of Virginia School of Medicine, Charlottesville, VA 29908. Address reprint requests to Dr. Wilson, Department of Internal Medicine, University of Iowa, SW54-GH, Iowa City, IA 52242. 1991.

Received for publication 5 October 1990 and in revised form 29 May

J. Clin. Invest.

(c) The American Society for Clinical Investigation, Inc.

$0021-9738 / 91 / 11 / 1511 / 11 \quad \$ 2.00$

Volume 88, November 1991, 1511-1521 the human host during the bite of an infected sandfly vector. It is phagocytosed by a mononuclear phagocyte, after which it converts into the obligate intracellular amastigote form (1). In vitro models have documented that promastigotes attach to several receptors on the surface of the macrophage before phagocytosis (2-4). This receptor-mediated ingestion is accompanied by an oxidative burst of the phagocyte, during which oxidants such as superoxide and hydrogen peroxide $\left(\mathrm{H}_{2} \mathrm{O}_{2}\right)$ are formed (5-7). Therefore, in order to successfully establish an infection promastigotes must survive despite the local production of toxic oxidant species by the mononuclear phagocyte.

L. donovani promastigotes are susceptible to killing in vitro by $\mathrm{H}_{2} \mathrm{O}_{2}$ in the absence of peroxidase, similar to the conditions that exist in a macrophage (8). The exact mechanism of $\mathrm{H}_{2} \mathrm{O}_{2}-$ mediated killing, and the factors that allow parasites to survive in the face of its production, have yet to be delineated. Hydrogen peroxide can be converted to hydroxyl radical $(\cdot \mathrm{OH})^{1}$ through the Fenton reaction in the presence of a source of iron: $\mathrm{H}_{2} \mathrm{O}_{2}+\mathrm{Fe}^{2+} \rightarrow \cdot \mathrm{OH}+\mathrm{OH}^{-}+\mathrm{Fe}^{3+}$. Hydroxyl radical is a highly toxic species that has been implicated in the killing of microorganisms by phagocytes $(9,10)$, as well as phagocyte-associated inflammation and tissue injury (11). Although one study found that scavengers of $\cdot \mathrm{OH}$ did not prevent $\mathrm{H}_{2} \mathrm{O}_{2}$ toxicity for one strain of $L$. donovani promastigotes when present in the extracellular promastigote environment (12), it remains to be seen whether the intracellular formation of $\cdot \mathrm{OH}$, catalyzed by endogenous promastigote iron, might mediate the toxic effects of $\mathrm{H}_{2} \mathrm{O}_{2}$.

When cultivated in liquid medium, L. major promastigotes transform from a less infectious form during log-phase growth to a highly infectious "metacyclic" promastigote when they reach stationary phase $(13,14)$. This development is accompanied by an increased ability to survive intracellularly in macrophages. The amount or physicochemical structure of several promastigote molecules has been found to change during development to stationary phase in studies of various Leishmania $\mathrm{sp}$. These molecules include the major surface glycolipid gp63 in $L$. braziliensis and $L$. d. chagasi $(15,16)$, the glycolipid lipophosphoglycan in L. major and other Old World Leishmania $s p .(17,18)$, and mRNA for the heat shock protein hsp70 in L. major (19). What role if any these changes play in the increased survival of stationary-phase promastigotes has yet to be determined.

Given the necessity for avoiding the toxic effects of macrophage generated $\mathrm{H}_{2} \mathrm{O}_{2}$ in order to cause infection, several hy-

1. Abbreviations used in this paper: DMPO, 5,5 dimethyl-1-pyrroline$\mathrm{N}$-oxide; DMPO/. $\mathrm{CH}_{3}, 2,2,5$ trimethyl-1-pyrrolidinyloxyl; DMPO/ - OH, 2,2 dimethyl-5-hydroxyl-1-pyrrolidinyloxyl; DTPA, diethylenetriaminepentaacetic acid; EPR, electron paramagnetic resonance spectrometry; $\cdot \mathrm{OH}$, hydroxyl radical. 
potheses might account for the differential survival of the different forms of promastigotes. First, it is possible that $\mathrm{H}_{2} \mathrm{O}_{2}$ exerts its microbicidal effects by secondary generation of the toxic oxidant $\cdot \mathrm{OH}$. Secondly, the increased virulence of stationary-phase promastigotes might be due to the formation of a lesser amount of $\cdot \mathrm{OH}$ or an increased resistance to its effects. Finally, the increased virulence that occurs during stationary phase may be triggered in part by environmental stimuli encountered by the promastigote during its life cycle, similar to the starvation-induced protection against both heat and oxidative killing observed in some bacteria (20). The present study is designed to examine each of these hypotheses using Leishmania donovani chagasi, a South American strain of L. donovani.

\section{Methods}

Parasites. L. d. chagasi, originally isolated from a patient in Brazil, was kindly provided by Richard Pearson, University of Virginia, Charlottesville. Parasites were maintained by serial intracardiac injection in hamsters. Amastigotes were isolated from the spleens of heavily infected hamsters as previously described (21), and allowed to convert to promastigotes at $26^{\circ} \mathrm{C}$ in a modified minimal essential medium containing $10 \%$ heat-inactivated fetal calf serum and $5.4 \mu \mathrm{g}$ of hemin $/ \mathrm{ml}$ (22). Unless otherwise indicated, experiments were performed using promastigotes within $21 \mathrm{~d}$ after isolation from a hamster. Promastigote cultures were initiated at $1 \times 10^{6}$ parasites $/ \mathrm{ml}$ and harvested for study either 1-3 d later during log phase or 6-7 d later during stationary phase of growth. The growth phases were differentiated by morphologic and concentration criteria as follows: log-phase cultures contained parasites that were ovoid to cigar-shaped (dimensions 1-3 $\times 3$ $10 \mu \mathrm{m}$ ) and frequently contained dividing forms (or rosettes), at a concentration between 4 and $8 \times 10^{6}$ promastigotes $/ \mathrm{ml}$. Stationary-phase cultures contained needle-shaped organisms $(1-2 \times 14-18 \mu \mathrm{m})$ at a concentration between 5 and $7 \times 10^{7}$ promastigotes $/ \mathrm{ml}$. Microscopic characterization of the numbers of promastigote forms with log- or stationary-like morphology in cultures revealed that cultures used as "stationary phase" contained between $98 \%$ and $99 \%$ promastigotes with stationary-like morphology, whereas "log phase" cultures contained $89-96 \%$ promastigotes with log-like morphology. Thus both types of cultures probably contained a few contaminating parasites of the opposite form.

Mouse infections. $1 \times 10^{7}$ promastigotes in log or stationary phase were suspended in $100 \mu \mathrm{l}$ of $5 \%$ heat-inactivated autologous mouse serum in medium 199 (University of Iowa Cancer Center facility) and administered to groups of 12 BALB/c mice (Harlan Sprague Dawley) through a tail vein. After 4,6 , or 8 wk of incubation, four animals from each group were killed and their liver and spleen parasite loads were determined microscopically according to the method of Stauber (23). Results were calculated in LD units, equivalent to the amastigote/ mononuclear cell ratio $\times$ the organ weight $(\mathrm{mg})$.

Assessment of promastigote viability according to motility. Promastigotes were harvested from log- or stationary-phase cultures and washed twice by centrifugation at $1,200 \mathrm{~g}\left(4^{\circ} \mathrm{C}\right)$ for $15 \mathrm{~min}$ in HBSS with Na bicarbonate, pH 7.2 (University of Iowa Cancer Center). 1 $\times 10^{7}$ promastigotes were suspended in $1 \mathrm{ml}$ of HBSS for each condition. Baseline viability was quantified microscopically according to flagellar motility by grading a minimum of 200 promastigotes as motile (viable) or nonmotile (nonviable). Usually over $98 \%$ of promastigotes were viable prior to $\mathrm{H}_{2} \mathrm{O}_{2}$ exposure; experiments with $<95 \%$ baseline viability were discounted. Promastigotes were then incubated in $0-1,200 \mu \mathrm{M} \mathrm{H}_{2} \mathrm{O}_{2}$ in HBSS for $60 \mathrm{~min}$. The reaction was stopped by the addition of catalase $(500 \mathrm{U} / \mathrm{ml})$, and motility (viability) was reassessed microscopically. These values are presented as percentage of promastigotes that remained motile after incubation in $\mathrm{H}_{2} \mathrm{O}_{2}$ or buffer.
All experiments were repeated a minimum of three times. Figures contain representative experiments demonstrating consistently repeatable patterns of the toxic effects of $\mathrm{H}_{2} \mathrm{O}_{2}$ on motility.

During some viability assays promastigotes were preincubated with deferoxamine $500 \mu \mathrm{g} / \mathrm{ml}$ for $30 \mathrm{~min}$ before the addition of $\mathrm{H}_{2} \mathrm{O}_{2}$, in order to explore the role of redox active promastigote iron in $\mathrm{H}_{2} \mathrm{O}_{2}$ toxicity. Control parasites were preincubated with no deferoxamine or with deferoxamine that was loaded with stoichiometric amounts of $\mathrm{FeCl}_{3}$, to establish that the effects were indeed due to the iron-chelating properties of deferoxamine. Motility was determined microscopically as above.

Measurements of protein and RNA synthesis. Triplicate samples of $100 \mu \mathrm{l}$ of promastigotes at $1.4 \times 10^{7} / \mathrm{ml} \mathrm{HBSS}$ were exposed to varying concentrations of $\mathrm{H}_{2} \mathrm{O}_{2}$ at $26^{\circ} \mathrm{C}$. After $1 \mathrm{~h}$ one sample from each condition was assessed for motility as described above. The other two samples were incubated in $10 \%$ dialyzed heat-inactivated fetal calf serum in HBSS, and $2 \mu \mathrm{Ci}$ of either $\left[{ }^{3} \mathrm{H}\right] \mathrm{leucine}$ or $\left[{ }^{3} \mathrm{H}\right]$ uracil for measurement of protein or RNA synthesis, respectively. The reaction was stopped after 1 or $3 \mathrm{~h}$ with $1 \%$ SDS and an excess of unlabeled leucine or uracil, respectively. Macromolecules were precipitated with $2 \mathrm{~N}$ trichloroacetic acid (TCA, $4^{\circ} \mathrm{C}, 60 \mathrm{~min}$.). The latter were collected onto glass filters (Whatman, Inc., Clifton NJ), washed with 0.3 N TCA, and incorporated counts were quantitated in a scintillation counter (Beckman Instruments, Inc., Palo Alto, CA). Data is presented as the mean of duplicate samples. Studies correlating promastigote motility with protein or RNA synthesis were repeated three times.

To determine the optimal actinomycin $D$ concentration for preventing transcription during heat shock experiments, RNA synthesis was measured in the presence or absence of the inhibitor. Log-phase promastigotes in $10 \%$ dialyzed heat-inactivated fetal calf serum/HBSS were preincubated in $1.0-60 \mu \mathrm{g}$ of actinomycin $\mathrm{D} / \mathrm{ml}$ (Sigma Chemical Co., St. Louis, MO). Incorporation of $\left[{ }^{3} \mathrm{H}\right]$ uracil was measured as above. Preliminary studies revealed that $10 \mu \mathrm{g}$ of cycloheximide $/ \mathrm{ml}$ was also needed to stabilize newly synthesized RNA long enough to detect its presence in assays of total RNA synthesis. A similar stabilization of RNA with cycloheximide has been detected for individual mRNA transcripts $(24,25)$.

SDS-PAGE and immunoblotting. Promastigotes were allowed to grow at $26^{\circ} \mathrm{C}$ to $\log$ or stationary phase. Identical aliquots were transferred to either $37^{\circ} \mathrm{C}$ (heat shock) or $26^{\circ} \mathrm{C}$ (control) water baths for $2 \mathrm{~h}$. Heat-shocked or control promastigotes were pelleted by centrifugation $\left(1,200 \mathrm{~g}, 13 \mathrm{~min} ., 4^{\circ} \mathrm{C}\right)$ and denatured in SDS reducing buffer with 20 $\mu \mathrm{g} / \mathrm{ml}$ each of antipain and leupeptin. Proteins from $5 \times 10^{6}$ promastigotes $(\sim 25 \mu \mathrm{g})$ were applied to $10 \%$ running-3.5\% stacking SDS polyacrylamide gels and electrophoresed, according to the discontinuous method of Laemmli (26). Proteins were electrophoretically transferred to nitrocellulose, blocked with 3\% BSA in PBS, and incubated with a rat monoclonal antibody directed against a conserved epitope on Drosophila hsp70 (kindly provided by S. Lindquist, University of Chicago) (27). Immunoblots were incubated in a peroxidase-conjugated goat anti-rat IgG second antibody, and developed with 3,3'-diaminobenzidine and $\mathrm{H}_{2} \mathrm{O}_{2}$ as previously described (28).

Spin trapping. Promastigotes were suspended at $1.0 \times 10^{8} / \mathrm{ml}$ in HBSS containing $100 \mathrm{mM}$ 5,5, dimethyl-pyrroline-1-oxide (DMPO, Sigma Chemical Co.), $140 \mathrm{mM}$ DMSO, and $0.1 \mathrm{mM}$ diethylenetriaminepentaacetic acid (DTPA). After the addition of $\mathrm{H}_{2} \mathrm{O}_{2}$ (100-900 $\mu \mathrm{M})$ the suspension was transferred to a quartz flat electron paramagnetic resonance spectrometry (EPR) cell. EPR spectra were obtained using a model E104 EPR spectrometer (Varian Associates, Palo Alto, CA) located at the University of Iowa College of Medicine electron spin resonance facility. In this spin trapping system, hydroxyl radical generation is manifested as the DMPO/ $\cdot \mathrm{CH}_{3}$ spin adduct which yields a characteristic EPR spectrum $\left(A_{N}=16.3 \mathrm{G}, A_{H}=23.5 \mathrm{G}\right)$. Some experiments were performed in the absence of DMSO. Under these conditions spin trapping of hydroxyl radical yields a characteristic four-line spectrum $\left(A_{N}=A_{H}=14.9 \mathrm{G}\right)$ due to DMPO/. OH (29). Initial scans performed at $15,30,60$, and 90 min after the addition of $\mathrm{H}_{2} \mathrm{O}_{2}$ to either log- or stationary-phase promastigotes revealed that peak amplitudes 
increased to maximal levels by $30 \mathrm{~min}$ and remain stable thereafter. Representative $30 \mathrm{~min}$. scans are shown in figures.

Negative control spectra were generated by omitting one component from the reaction cuvette. In some cases catalase $(500 \mathrm{U} / \mathrm{ml})$, or promastigotes pretreated with deferoxamine or exposure to heat shock, were employed. Possible effects of log- or stationary-phase promastigotes on the stability of DMPO spin adducts was assessed by adding promastigotes to solutions of DMPO/ $\cdot \mathrm{CH}_{3}$ previously generated by mixing $\mathrm{H}_{2} \mathrm{O}_{2}(1 \mu \mathrm{M})$ and ferrous ammonium sulfate $(0.1 \mathrm{mM})$ in the presence of DMPO, DMSO, and DTPA. The spin adduct EPR peak amplitude was monitored over time relative to samples without promastigotes. Unless otherwise indicated EPR spectrometer settings were: microwave power, $20 \mathrm{MW}$; modulation amplitude, $1.0 \mathrm{G}$; modulation frequency, $100 \mathrm{kHz}$; time constant, $2 \mathrm{~s}$; sweep rate, $12.5 \mathrm{G} / \mathrm{min}$; and gain, $6.3 \times 10^{4}$.

Preparation of promastigote membranes and cytosol. Promastigotes in $\log$ or stationary phase of growth were incubated at $3.0 \times 10^{8}$ parasites $/ \mathrm{ml}$ in $\mathrm{ddH}_{2} \mathrm{O}$ at $4^{\circ} \mathrm{C}$ for $10 \mathrm{~min}$. They were disrupted after incubation at 500 psi for $15 \mathrm{~min}$. in a nitrogen cell disruption chamber (Parr Instruments, Rock Island, IL). Large particles were removed by centrifugation at $750 \mathrm{~g}$ for $10 \mathrm{~min}$., and membranes were pelleted at $100,000 \mathrm{~g}$ for $1 \mathrm{~h}$. The cytosolic fraction (supernatant) was removed, and the pellet containing membranes was rinsed in $\mathrm{ddH}_{2} \mathrm{O}$, centrifuged once more for $5 \mathrm{~min}$, and resuspended to the starting volume in PBS. Final pH measurements were 6.5 and 7.2 in the cytosolic and membrane fractions, respectively. Membrane or cytosolic fractions were assayed for $\cdot \mathrm{OH}$ production after the addition of $600 \mu \mathrm{M} \mathrm{H}_{2} \mathrm{O}_{2}$ using spin trapping.

\section{Results}

Susceptibility of log- or stationary-phase promastigotes to $\mathrm{H}_{2} \mathrm{O}_{2}$-mediated toxicity. Intravenous administration of $L$.d. chagasi promastigotes results in a chronic infection of BALB/c mice, measured by sequential estimates of liver and spleen parasite loads. $L$. major promastigotes increase in infectivity as they develop from log to a highly infectious "metacyclic" stage dur-

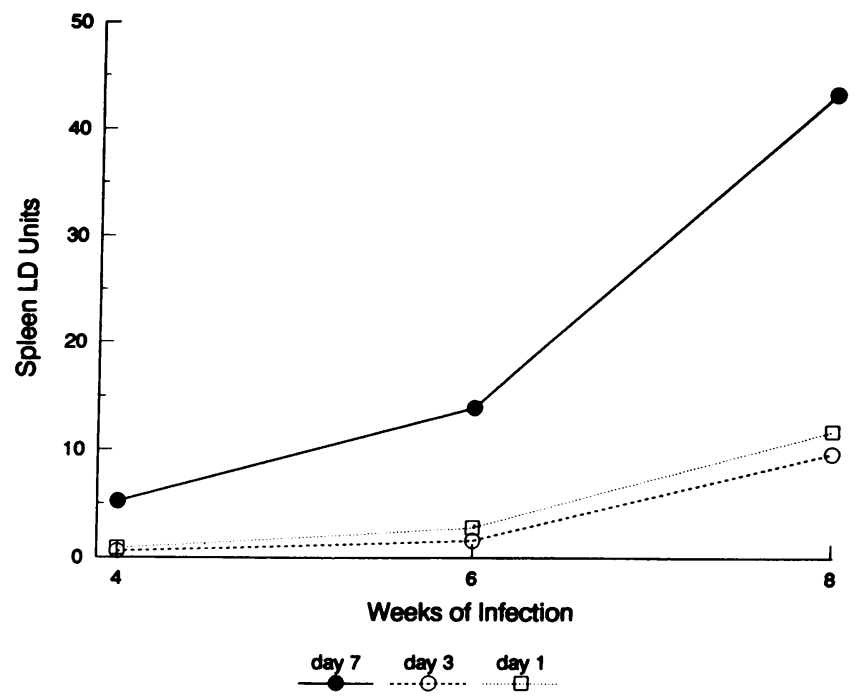

Figure 1. Infection of BALB/c mice with log-phase (day 1 or 3 ) or stationary-phase (day 7) Leishmania donovani chagasi promastigotes. Mice were injected i.v. with $1 \times 10^{7}$ promastigotes harvested from cultures during either $\log$ or stationary phase of growth. They were sacrificed after 4,6 , or $8 \mathrm{wk}$ and their liver and spleen parasite loads were quantified as LD units (defined in the text). Shown are the mean splenic LD units for groups of four mice at each time point.
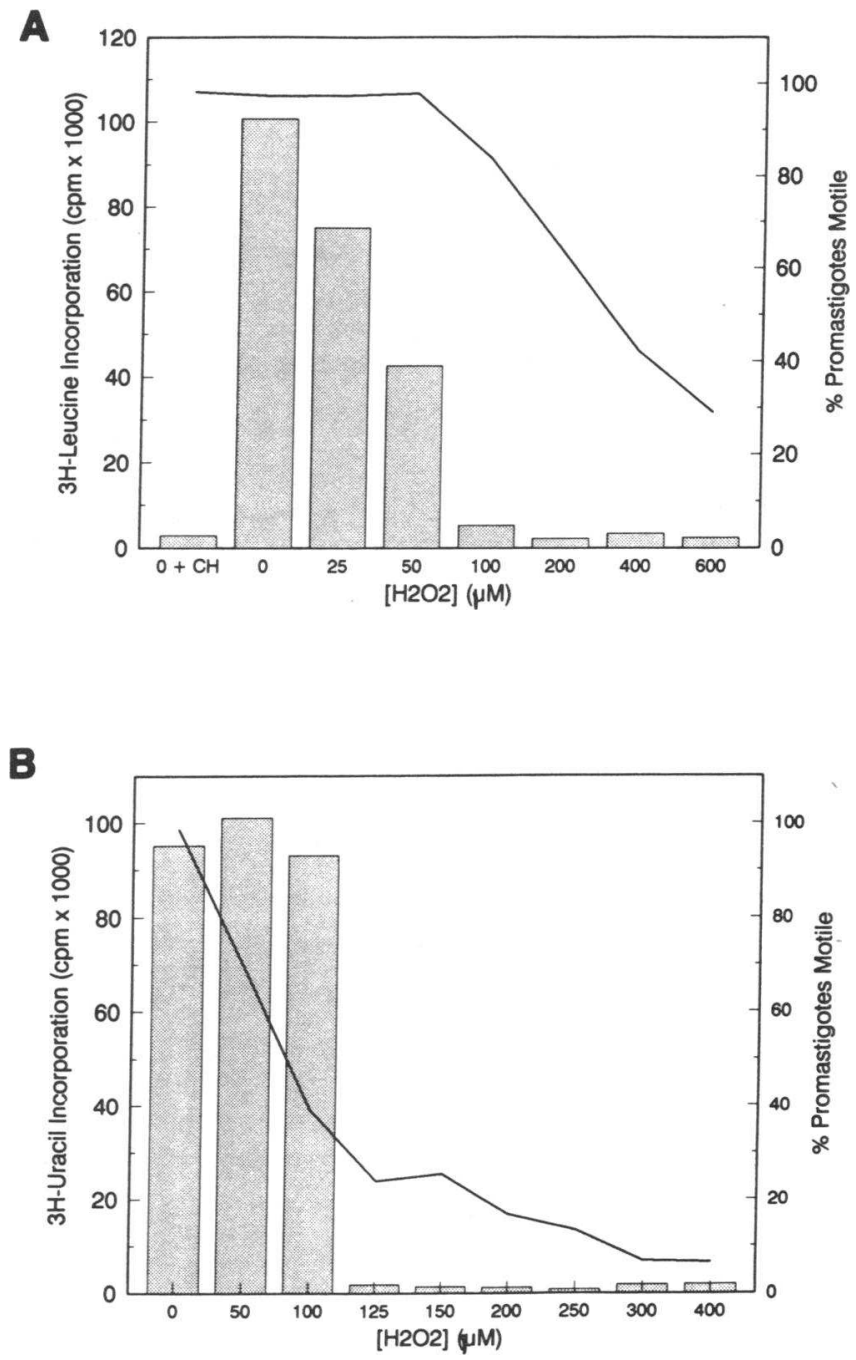

Figure 2. Correlation of promastigote motility with protein and RNA synthesis. $(A)$ Triplicate samples of log-phase promastigotes in HBSS were exposed to different concentrations of $\mathrm{H}_{2} \mathrm{O}_{2}$ for $1 \mathrm{~h}$. One sample was assayed for motility as in Fig. 2, and the other (duplicate) samples were assessed for incorporation of $\left[{ }^{3} \mathrm{H}\right]$ leucine into trichloracetic acid precipitable proteins over a 3-h period. Shown is a representative experiment with mean cpm $\left[{ }^{3} \mathrm{H}\right]$ leucine incorporated (bars) and \% promastigotes remaining motile (line drawing) after exposure to $\mathrm{H}_{2} \mathrm{O}_{2}$. (B) Log-phase promastigotes were exposed to $\mathrm{H}_{2} \mathrm{O}_{2}$ and assessed for either motility (line drawing) or incorporation of $\left[{ }^{3} \mathrm{H}\right]$ uracil into trichloracetic acid-precipitable RNA (mean of duplicates in bars).

ing stationary-phase growth $(13,14)$. Similarly, we found that the virulence of $L$. d. chagasi promastigotes increased as they developed from $\log$ to stationary phase during in vitro cultivation (Fig. 1). During these studies log-phase promastigotes were isolated on day 1 or 3 of cultivation, and stationary phase promastigotes were isolated on day 7 of growth. Log and stationary phases were defined by morphologic and concentration criteria as outlined in the Methods section.

Exposure of promastigotes in log phase growth to increasing amounts of $\mathrm{H}_{2} \mathrm{O}_{2}$ resulted in increasing toxicity, measured by an assay of promastigote motility (Fig. $2 A$ and $B$, line graphs). Channon and Blackwell (30), using a similar assay, found that the motility of Sudanese strain $L$. donovani promas- 
tigotes correlates with survival, as measured by the ability of promastigotes to take up the vital dyes ethidium bromide and fluorescein diacetate $24 \mathrm{~h}$ after exposure to $\mathrm{H}_{2} \mathrm{O}_{2}$. Because $L$. $d$. chagasi promastigotes did not take up these dyes either in their native state or after exposure to $\mathrm{H}_{2} \mathrm{O}_{2}$, we correlated promastigote motility with the ability of promastigotes to synthesize protein or RNA after exposure to $\mathrm{H}_{2} \mathrm{O}_{2}$ as a measure of viability. Protein synthesis (incorporation of $\left[{ }^{3} \mathrm{H}\right]$ leucine) decreased in a dose-dependent manner after exposure to $\mathrm{H}_{2} \mathrm{O}_{2}$, reaching background levels at lower $\mathrm{H}_{2} \mathrm{O}_{2}$ concentrations than those that resulted in loss of motility (Fig. $2 \mathrm{~A}$, bars). A similar decrease in RNA synthesis (incorporation of $\left[{ }^{3} \mathrm{H}\right]$ uracil) was observed after exposure to $\mathrm{H}_{2} \mathrm{O}_{2}$, although there was a sudden drop in RNA synthesis compared to a more gradual drop in motility, with increasing $\mathrm{H}_{2} \mathrm{O}_{2}$ concentrations (Fig. $2 \mathrm{~B}$, bars). Thus, the $\mathrm{H}_{2} \mathrm{O}_{2}$-induced loss of motility was accompanied by a cessation of protein and RNA synthesis.

Because virulence must be accompanied by the ability to evade or resist the microbicidal effects of macrophage $\mathrm{H}_{2} \mathrm{O}_{2}$, we measured the toxicity of $\mathrm{H}_{2} \mathrm{O}_{2}$ for log- or stationary-phase promastigotes using the same motility assay. L. d. chagasi promastigotes were harvested during their transition from log (days 2 and 3 ) to stationary (day 6) phase of growth in vitro, and exposed to varying concentrations of $\mathrm{H}_{2} \mathrm{O}_{2}$ at $26^{\circ} \mathrm{C}$ (Fig. 3 ). There was a dose-dependent loss of promastigote motility after $\mathrm{H}_{2} \mathrm{O}_{2}$ exposure during both phases of growth. However, the $\mathrm{H}_{2} \mathrm{O}_{2}$ concentration required to produce that toxic effect increased as promastigotes progressed from $\log$ to stationary phase. For instance, the motility of log-phase promastigotes (day 2) after exposure to $200 \mu \mathrm{M} \mathrm{H} \mathrm{H}_{2} \mathrm{O}_{2}$ for $1 \mathrm{~h}$ was $<30 \%$ (compared to nearly $100 \%$ in promastigotes not exposed to $\mathrm{H}_{2} \mathrm{O}_{2}$ ). In contrast, stationary phase promastigotes (day 6) exposed to $200 \mu \mathrm{M} \mathrm{H}_{2} \mathrm{O}_{2}$ retained $>90 \%$ motility. Thus, the $50 \%$ toxicity $\left(\mathrm{LD}_{50}\right)$ dose of $\mathrm{H}_{2} \mathrm{O}_{2}$ increased from $\sim 150$ to $275 \mu \mathrm{M}$

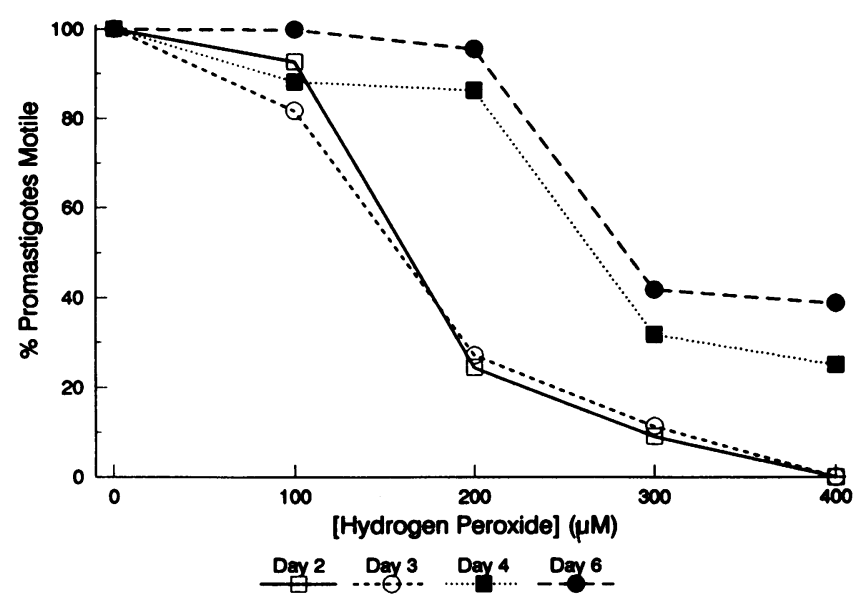

Figure 3. Toxicity of $\mathrm{H}_{2} \mathrm{O}_{2}$ for promastigotes in log- or stationaryphase growth. On successive days during their development from log to stationary phase, promastigotes from the same original culture were washed and suspended in the indicated concentrations of $\mathrm{H}_{2} \mathrm{O}_{2}$. Toxicity was assessed microscopically as described in the text. Plots represent the percent of promastigotes that remained motile after $\mathrm{H}_{2} \mathrm{O}_{2}$ exposure, during a representative experiment. Three duplicate experiments showed identical patterns. Promastigotes from days 2 and 3 represent log, day 4 represent transitional, and day 6 represent stationary phases of growth. as promastigotes developed from log to stationary phase. Other experiments revealed that higher concentrations of $\mathrm{H}_{2} \mathrm{O}_{2}$ resulted in immobilization of $100 \%$ of stationary-phase promastigotes (not shown).

Considerable variation in susceptibility of control promastigotes to $\mathrm{H}_{2} \mathrm{O}_{2}$-mediated injury was noted over the course of our experiments, as reflected in Fig. $2 A$ relative to Fig. $2 B$ and 3. This variability was probably due to a number of factors, one of which was the length of cultivation in vitro. We observed that a single culture maintained for several weeks in vitro was immobilized by lower $\mathrm{H}_{2} \mathrm{O}_{2}$ concentrations after increasing lengths of cultivation. For example, serial studies of one culture revealed an $\mathrm{LD}_{50}$ of over $850 \mu \mathrm{M}$ within the first 2 wk after isolation from a hamster spleen, which fell to between 220 and $460 \mu \mathrm{M} \mathrm{H}_{2} \mathrm{O}_{2}$ after cultivation in liquid medium for 18-25 d. Nevertheless, these differences do not confound our results, as all experiments performed included a paired control sample for the promastigote population under study.

Effect of chelating endogenous promastigote iron on $\mathrm{H}_{2} \mathrm{O}_{2}$ toxicity. $\cdot \mathrm{OH}$ has been implicated as a primary oxidant responsible for $\mathrm{H}_{2} \mathrm{O}_{2}$ cytotoxicity toward some microbes $(9,10)$. Iron is required for the generation of $\cdot \mathrm{OH}$ from $\mathrm{H}_{2} \mathrm{O}_{2}$ via the Fenton reaction. As a means of investigating a possible role of $\cdot \mathrm{OH}$ in $\mathrm{H}_{2} \mathrm{O}_{2}$-mediated killing of $L$. $d$. chagasi, the effect of chelating endogenous promastigote iron on $\mathrm{H}_{2} \mathrm{O}_{2}$-mediated toxicity was studied. Promastigotes were preincubated in different concentrations of deferoxamine, deferoxamine that had been saturated with stoichiometric amounts of $\mathrm{FeCl}_{3}$, or buffer (control) before exposure to $1,000 \mu \mathrm{M} \mathrm{H}_{2} \mathrm{O}_{2}$. The resultant viability was assessed according to promastigote motility. As shown in Fig. 4 $A$, increasing concentrations of deferoxamine resulted in increasing protection from $\mathrm{H}_{2} \mathrm{O}_{2}$-mediated toxicity, but deferoxamine that had been saturated with stoichiometric amounts of $\mathrm{FeCl}_{3}$ did not have a protective effect. This suggests that the increased resistance was indeed due to the iron-chelating capacity of deferoxamine. Fig. $4 \mathrm{~B}$ shows the effect of different $\mathrm{H}_{2} \mathrm{O}_{2}$ concentrations on the motility of promastigotes preincubated with buffer (control), $0.5 \mathrm{mg} / \mathrm{ml}$ deferoxamine, or iron-saturated deferoxamine. Again, deferoxamine offered protection of promastigotes against the toxic effects of $\mathrm{H}_{2} \mathrm{O}_{2}$. However, during this experiment preincubation of parasites with iron-saturated deferoxamine only partially abrogated the protection owing to deferoxamine. We suspect that this was because the ironbinding sites in deferoxamine were only partially "saturated." $\mathrm{FeCl}_{3}$ alone was toxic for promastigotes, so it was not possible to overcome the deferoxamine with an excess of iron. To avoid this confounding problem we were careful not to oversaturate the deferoxamine in the system, and in some assays it is very likely that we inadvertantly under-saturated the deferoxamine (see $0.5 \mu \mathrm{g} / \mathrm{ml}$ bars in Fig. $4, A$ and $B$ ). We also determined that the motility of promastigotes preincubated in deferoxamine and washed by centrifugation before $\mathrm{H}_{2} \mathrm{O}_{2}$ exposure was comparable to that of promastigotes exposed to $\mathrm{H}_{2} \mathrm{O}_{2}$ with deferoxamine still in the system. Thus, the protection afforded by deferoxamine was probably not due to a direct interaction between deferoxamine and $\mathrm{H}_{2} \mathrm{O}_{2}$.

Deferoxamine alone $(0.5 \mathrm{mg} / \mathrm{ml})$ did not interfere with the motility of control promastigotes $(90.3 \%$ of promastigotes were motile in the absence, and $94.3 \%$ motile in the presence of deferoxamine). Furthermore, protein synthesis was unchanged in promastigotes after the addition of deferoxamine. 211,010, 253,490 , and $194,563 \mathrm{cpm}$ of $\left[{ }^{3} \mathrm{H}\right]$ leucine were incorporated 
A

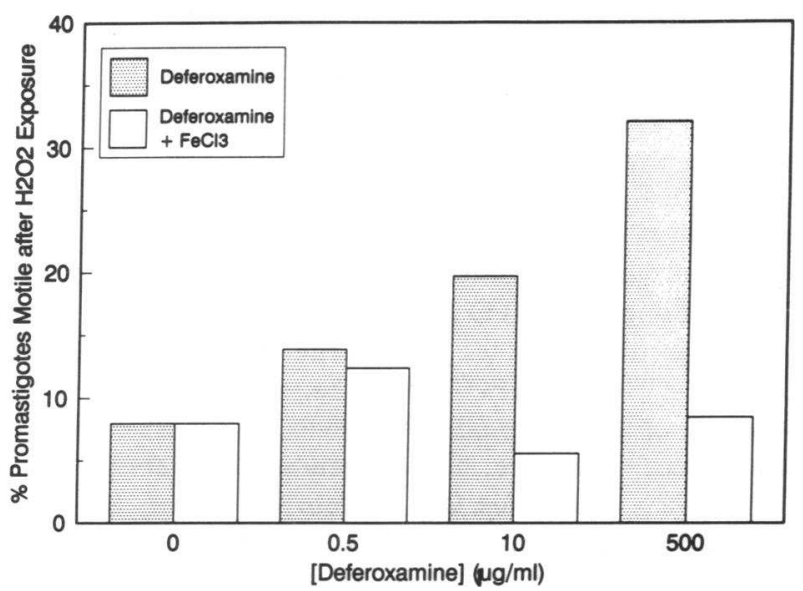

B

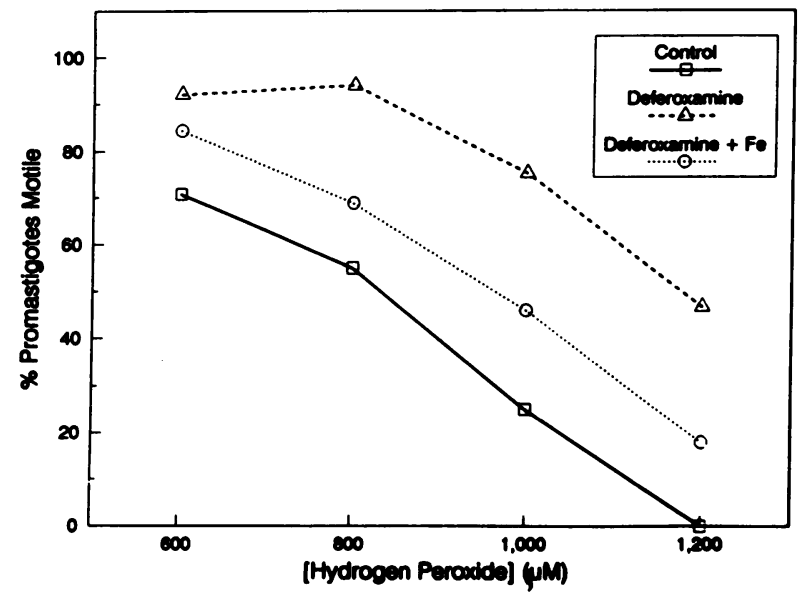

Figure 4. Effect of deferoxamine on toxicity of $\mathrm{H}_{2} \mathrm{O}_{2}$ for promastigotes. $(A)$ Log-phase promastigotes were preincubated in the indicated concentrations of deferoxamine or deferoxamine loaded with stoichiometric amounts of $\mathrm{FeCl}_{3}$ for $60 \mathrm{~min}$. Parasites were then exposed to $1,000 \mu \mathrm{M} \mathrm{H}_{2} \mathrm{O}_{2}$ and toxicity was assessed according to promastigote motility. Control promastigotes preincubated in buffer alone or buffer with iron-saturated deferoxamine, but not exposed to $\mathrm{H}_{2} \mathrm{O}_{2}$, exhibited $96 \%$ and $97.2 \%$ motility, respectively. $(B)$ Log-phase promastigotes were preincubated in $0.5 \mathrm{mg} / \mathrm{ml}$ deferoxamine, deferoxamine loaded with stoichiometric amounts of $\mathrm{FeCl}_{3}$, or buffer. Susceptibility to $\mathrm{H}_{2} \mathrm{O}_{2}$ toxicity was assessed microscopically according to promastigote motility as above.

into TCA-precipitable proteins over $3 \mathrm{~h}$ in the presence of 0 , 0.05 , or $0.5 \mathrm{mg} / \mathrm{ml}$ deferoxamine, respectively. In contrast, $4,219 \mathrm{cpm}$ of $\left[{ }^{3} \mathrm{H}\right]$ leucine were incorporated in the presence of the protein synthesis inhibitor cycloheximide $(10 \mu \mathrm{g} / \mathrm{ml})$.

Murray (12) found that scavengers of $\cdot \mathrm{OH}$ such as mannitol did not prevent the toxic effects of $\mathrm{H}_{2} \mathrm{O}_{2}$ for $L$. donovani, leading him to conclude that $\cdot \mathrm{OH}$ was not necessary for $\mathrm{H}_{2} \mathrm{O}_{2-}$ mediated killing. We performed similar studies using $L$. d. chagasi, and in contrast to his findings we noted that mannitol afforded partial protection of this strain against $\mathrm{H}_{2} \mathrm{O}_{2}$ toxicity (Fig. 5).

Role of hydroxyl radical in $\mathrm{H}_{2} \mathrm{O}_{2}$ toxicity. The above studies documented the importance of iron in $\mathrm{H}_{2} \mathrm{O}_{2}$ toxicity, suggest-

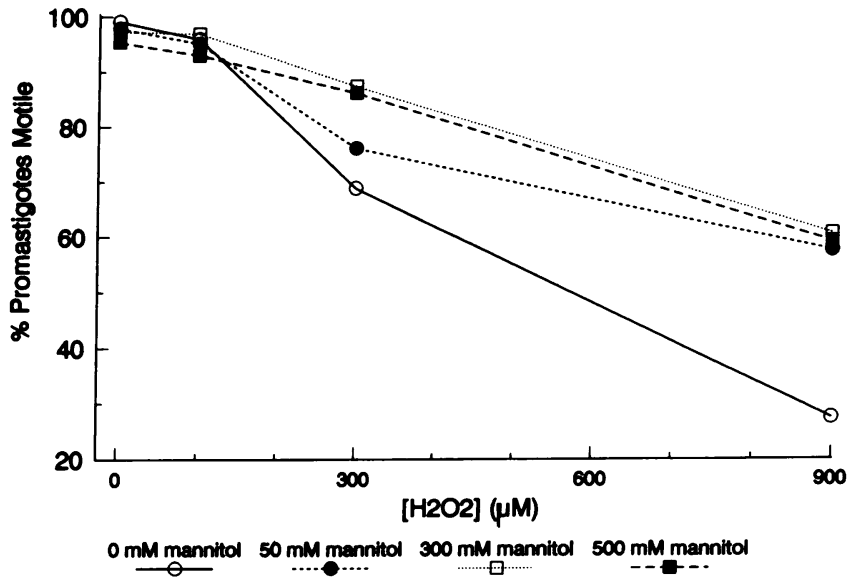

Figure 5. Partial protection of promastigotes against $\mathrm{H}_{2} \mathrm{O}_{2}$ toxicity with mannitol. Log-phase promastigotes in HBSS were incubated in the indicated concentrations of mannitol for $30 \mathrm{~min}$., then exposed to different concentrations of $\mathrm{H}_{2} \mathrm{O}_{2}$ for $1 \mathrm{~h}$. The reaction was stopped by the addition of catalase, and motility was assessed.

ing that a component of the toxic effect might be due to the formation of $\cdot \mathrm{OH}$ via the Fenton reaction. Accordingly, spin trapping was used to confirm the generation of $\cdot \mathrm{OH}$ after the addition of $\mathrm{H}_{2} \mathrm{O}_{2}$ to promastigotes. When produced in the presence of DMSO and the spin trap DMPO, $\cdot \mathrm{OH}$ leads to formation of the stable methyl radical spin adduct of DMPO, $\mathrm{DMPO} / \cdot \mathrm{CH}_{3}(29)$. This spin adduct yields a characteristic sixline spectrum $\left(A_{N}=16.3 \mathrm{G}, A_{H}=23.5 \mathrm{G}\right)$ when examined by EPR spectroscopy. The amplitude of each spectral peak correlates with the amount of spin adduct formed and therefore the amount of $\cdot \mathrm{OH}$ generated over time $(31) . \mathrm{H}_{2} \mathrm{O}_{2}$ was added to $\log$ phase $L$. d. chagasi promastigotes in the presence of DMPO and DMSO. The resulting EPR spectrum was that of DMPO/ $\cdot \mathrm{CH}_{3}$ and to a lesser extent the hydroxyl radical spin adduct DMPO/. OH (Fig. $6 \mathrm{~A}, \mathrm{Log}$ ). A similar spectrum could be generated in a cell-free $\cdot \mathrm{OH}$-generating system with the addition of $\mathrm{FeCl}_{2}$ and $\mathrm{H}_{2} \mathrm{O}_{2}$ in the presence of DMPO, DMSO, and DTPA (Fig. $6 \mathrm{~A}, \mathrm{Fe}$ ). These data are consistent with spin trapping of $\cdot \mathrm{OH}$ after addition of $\mathrm{H}_{2} \mathrm{O}_{2}$ to promastigotes. The omission of promastigotes or $\mathrm{H}_{2} \mathrm{O}_{2}$ resulted in EPR spectra that lacked evidence of DMPO spin adducts (Fig. $6 \mathrm{~A}, \mathrm{Med}$ ). Furthermore, preincubation of promastigotes in deferoxamine prevented the formation of $\cdot \mathrm{OH}$ in these solutions (Fig. $6 \mathrm{~A}$, Dsf). Consistent with the ability of mannitol to limit $\mathrm{H}_{2} \mathrm{O}_{2}$-mediated injury (Fig. 5), $50 \mathrm{mM}$ mannitol also inhibited the magnitude of $\cdot \mathrm{OH}$-derived spin adducts after the addition of $\mathrm{H}_{2} \mathrm{O}_{2}$ to promastigotes (data not shown). The magnitude of $\cdot \mathrm{OH}$ derived spin adducts increased when increasing concentrations of $\mathrm{H}_{2} \mathrm{O}_{2}$ were added to promastigote suspensions. The concentrations of $\mathrm{H}_{2} \mathrm{O}_{2}$ required to generate $\cdot \mathrm{OH}$-induced spin adducts were similar to those that had toxic effects on promastigote motility.

The amount of $\cdot \mathrm{OH}$ generated by exposure of log- or stationary-phase promastigotes to $\mathrm{H}_{2} \mathrm{O}_{2}$ was determined. Lesser magnitudes of $\cdot \mathrm{OH}$ generated spin adducts were detected after the addition of the same concentration of $\mathrm{H}_{2} \mathrm{O}_{2}$ to stationaryphase (Fig. 6 A, Sta) than to log-phase (Fig. 6 A, Log) promastigotes, as indicated by the lesser amplitude of spectral peaks. To eliminate the possibility that DMSO was altering promastigote 
A

$\log$

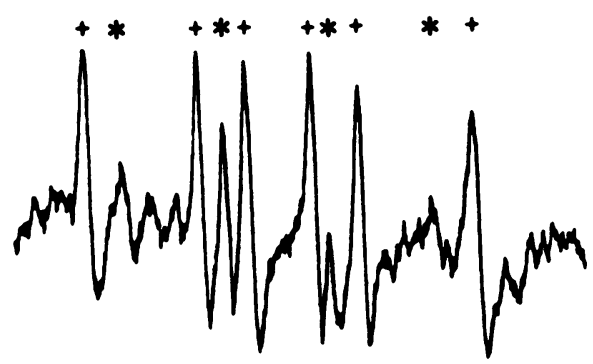

F•

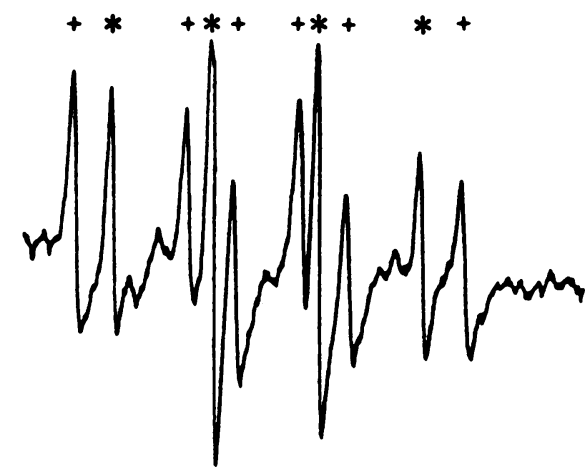

Med

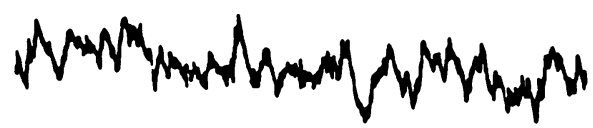

D \& 1

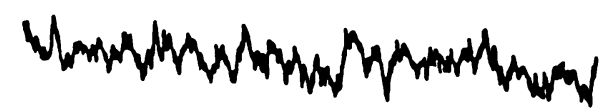

Sta

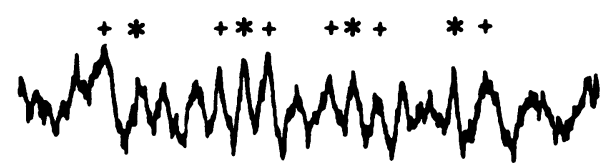

100

$\mathbf{B}$

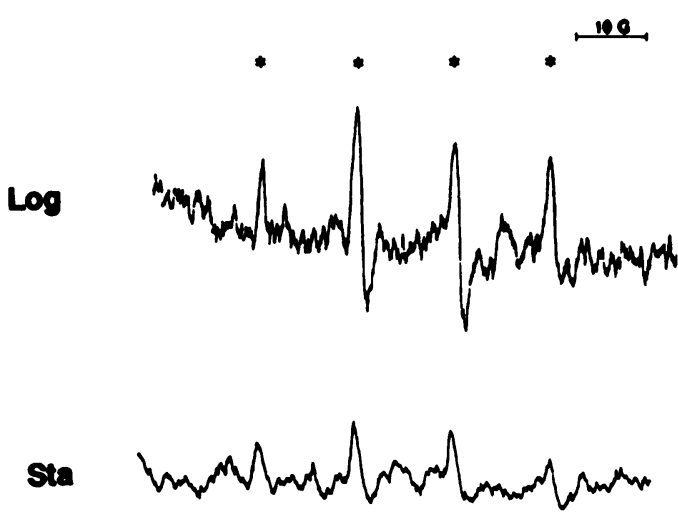

Figure 6. EPR spectra of promastigotes after addition of $\mathrm{H}_{2} \mathrm{O}_{2}$. $(A)$ The generation of $\cdot \mathrm{OH}$ was documented by spin trapping this species with DMPO and DMSO, yielding a characteristic spectrum of peaks corresponding to DMPO/. $\mathrm{CH}_{3}(+)$ and DMPO/. OH (*). Tracings show representative spectra generated $30 \mathrm{~min}$ after the addition of $\mathrm{H}_{2} \mathrm{O}_{2}$ to log-phase promastigotes $(\mathrm{Log}), \mathrm{FeCl}_{2}(\mathrm{Fe})$, culture medium without promastigotes $(\mathrm{Med}), \mathrm{log}$-phase promastigotes preincubated membrane permeability, DMSO was omitted from some experiments. This resulted in the generation of the stable spin adduct $\mathrm{DMPO} / \cdot \mathrm{OH}$, detected by a characteristic four-line spectrum. The amount of this spin adduct was lesser in stationary phase than in log phase organisms (Fig. $6 \mathrm{~B}$ ).

The inclusion of catalase to remove $\mathrm{H}_{2} \mathrm{O}_{2}$ prevented the formation of the $\cdot \mathrm{OH}$-generated spin adducts, in cuvettes that contained log- or stationary-phase promastigotes with either DMPO alone, or DMPO and DMSO. Neither log nor stationary phase promastigotes altered the stability of preformed $\mathrm{DMPO} / \cdot \mathrm{CH}_{3}$ or DMPO/ $\cdot \mathrm{OH}$, when parasites were added to solutions of these spin adducts previously generated in a cellfree system. Therefore, altered spin adduct stability did not explain these data. Thus, the apparent amount of $\cdot \mathrm{OH}$ formed correlated well with the amount of $\mathrm{H}_{2} \mathrm{O}_{2}$-mediated toxicity for promastigotes in the two phases of growth.

Generation of $\cdot \mathrm{OH}$ in cytosolic fractions of promastigotes. In order to provide insight into the location of the promastigote-associated catalyst leading to $\cdot \mathrm{OH}$ production, promastigotes in log or stationary phase of growth were lysed by nitrogen cavitation and cytosolic and membrane fractions were separated. Free radicals generated by the addition of $\mathrm{H}_{2} \mathrm{O}_{2}$ to these fractions was then determined in spin trapping studies. Representative spectra after the addition of $\mathrm{H}_{2} \mathrm{O}_{2}$ to fractions from log or stationary phase promastigotes are shown in Fig. 7. These spectra were generated using DMPO and DTPA but not DMSO. Therefore spectra are comparable to those generated from whole promastigotes in Fig. $6 \mathrm{~B}$. These spectra indicated that: $(a) \cdot \mathrm{OH}$ was generated upon the addition of $\mathrm{H}_{2} \mathrm{O}_{2}$ to the cytosolic but not to the membrane fractions from both growth phases, and $(b)$ the amount of $\cdot \mathrm{OH}$ generated was greater when cytosol from log as opposed to stationary phase promastigotes was used. Taking into account the different gains used to generate the "Log Cytosol" and the "Sta Cytosol" tracings in Fig. 7, the amount of $\cdot \mathrm{OH}$ generated upon the addition of $\mathrm{H}_{2} \mathrm{O}_{2}$ to cytosol from log-phase promastigotes was 3.2-fold greater than that generated in cytosol from stationary-phase promastigotes. These data suggest that spectra generated from intact organisms (Fig. 6) were due to spin trapping of $\cdot \mathrm{OH}$ generated at an intracellular site. Overall, a greater magnitude of $\cdot \mathrm{OH}$ was generated from promastigote cytosol than from intact cells (note the greater gain in Fig. 6 "Log" tracing as opposed to Fig. 7 "Log Cytosol" tracing). This could have been due to decreased penetration of the spin trap into intact cells, or to metabolism of $\mathrm{H}_{2} \mathrm{O}_{2}$ or spin adducts by intact parasites.

Effect of heat shock on $\mathrm{H}_{2} \mathrm{O}_{2}$-mediated toxicity. Exposure of eukaryotic or prokaryotic cells to environmental stimuli such as heat, $\mathrm{H}_{2} \mathrm{O}_{2}$, or agents that generate superoxide induces a heat shock response which is associated with the expression of new proteins including heat shock proteins $(31,32)$, and which is also sometimes associated with an increased resistance to oxidant-mediated injury (33). Therefore we examined whether heat shock of promastigotes might induce $\mathrm{H}_{2} \mathrm{O}_{2}$ resistance. During their natural life cycle promastigotes are transferred

in deferoxamine (Dsf), or stationary-phase promastigotes $($ Sta). $(B)$ EPR spectra of promastigotes in DMPO without DMSO exhibited a characteristic four-line spectrum of the $\cdot \mathrm{OH}$ adduct DMPO/.OH (*) after the addition of $\mathrm{H}_{2} \mathrm{O}_{2}$. Again, the magnitude of the spectral peaks, which correspond to the concentration of $\mathrm{DMPO} / \cdot \mathrm{OH}$, was less in stationary than in log-phase promastigotes. 

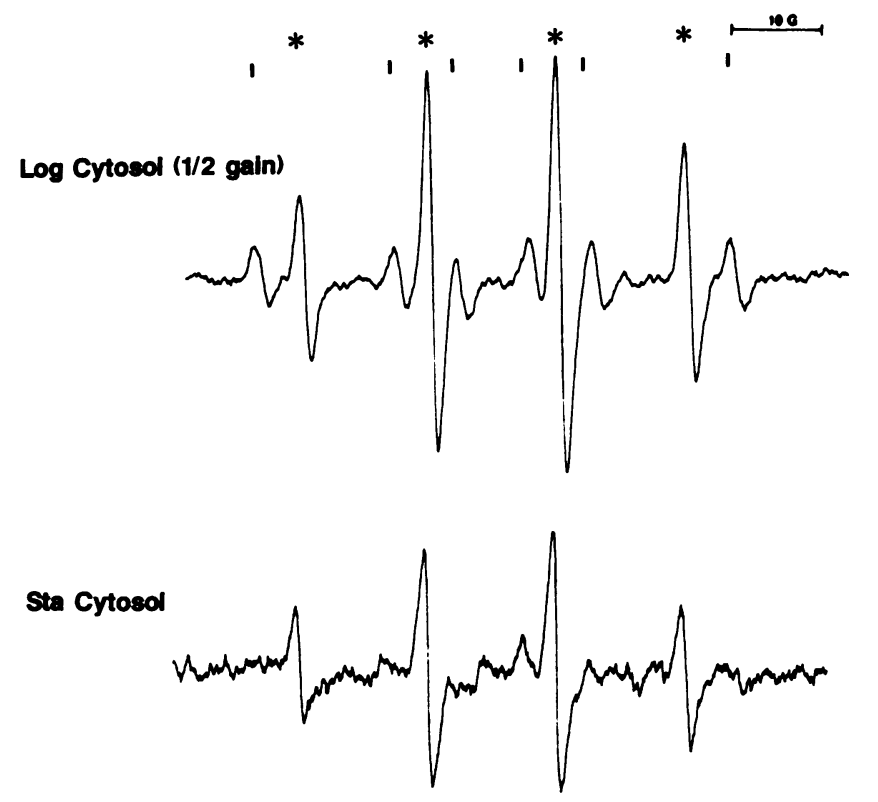

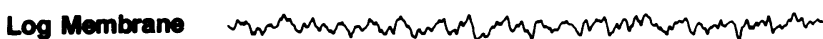

\section{Sta Membrano}

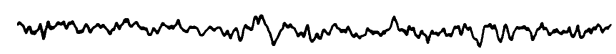

Figure 7. EPR spectra of fractionated promastigotes after the addition of $\mathrm{H}_{2} \mathrm{O}_{2}$. Membrane or cytosolic fractions were isolated from promastigotes in $\log (\mathrm{Log})$ or stationary $(\mathrm{Sta})$ phase of growth, and these were incubated with $\mathrm{H}_{2} \mathrm{O}_{2}(600 \mu \mathrm{M})$ in the presence of DMPO. Characteristic four-line spectra corresponding to the spin adduct DMPO/.OH (*) were detected using cytosolic but not membrane fractions. Note that the gain of the "Log Cytosol" tracing is one-half the gain of the other three spectra in this figure, and the spectra in Fig. 6. Thus, the amount of DMPO/.OH generated with cytosol from log-phase cells is proportional to twice the height of peaks in the spectrum shown, relative to the heights of peaks in the "Sta Cytosol" and both "Membrane" tracings. Of note, occasional spectra of cytosol fractions also contained a second nitroxide species $\left(A_{N}=16.1 \mathrm{G}, A_{H}\right.$ $=23.3 \mathrm{G}$ ), indicated by vertical lines $(\mathrm{l})$. The etiology of this radical remains unclear but could have resulted in part from small amounts of membrane contamination of the cytosol fraction, resulting in the generation of lipid radicals during $\cdot \mathrm{OH}$ generation and their subsequent spin trapping.

from $25^{\circ} \mathrm{C}$ to $37^{\circ} \mathrm{C}$ when they are inoculated by a sandfly vector into a mammalian host, which may constitute a natural "heat shock." Since the heat shock response of many cells occurs at $42^{\circ} \mathrm{C}$, we first investigated whether incubation of $L . d$. chagasi promastigotes at $37^{\circ} \mathrm{C}$ induced the production of one heat shock protein. Promastigotes in log- or stationary-phase growth were incubated at $26^{\circ} \mathrm{C}$ or $37^{\circ} \mathrm{C}$ for $2 \mathrm{~h}$. Lysates of these promastigotes were then analyzed by immunoblotting with a monoclonal antibody raised against Drosophila hsp70, which recognizes a shared hsp70 epitope found in widely divergent cell types (27). These blots documented that both stages of parasite expressed hsp70 constitutively, but there was an increase in the amount of hsp 70 after incubation at $37^{\circ} \mathrm{C}$ for $2 \mathrm{~h}$ (Fig. 8). Quantification by densitometry revealed that hsp70 increased 1.9-fold in log-phase parasites, and 1.4-fold in stationary-phase promastigotes. Thus by this one parameter, incubation for $2 \mathrm{~h}$ at $37^{\circ} \mathrm{C}$ constitutes a "heat shock" for $L$. $d$. chagasi promastigotes.

Log- or stationary-phase promastigotes were exposed to heat $\left(37^{\circ} \mathrm{C}\right)$ or maintained at $26^{\circ} \mathrm{C}$ (control), after which their susceptibility to $\mathrm{H}_{2} \mathrm{O}_{2}$ toxicity was determined according to the motility assay. Log-phase promastigotes had a dramatic increase in their resistance to $\mathrm{H}_{2} \mathrm{O}_{2}$ toxicity after exposure to heat for 1 or $2 \mathrm{~h}$. For example, after exposure to $200 \mu \mathrm{M} \mathrm{H}_{2} \mathrm{O}_{2}$, $<20 \%$ of control log-phase promastigotes remained motile. In contrast, $75 \%$ of log-phase promastigotes preincubated at $37^{\circ} \mathrm{C}$ for $2 \mathrm{~h}$ remained motile after a similar $\mathrm{H}_{2} \mathrm{O}_{2}$ exposure (Fig. 9, top panel). Stationary-phase promastigotes did not exhibit the same magnitude of protection against $\mathrm{H}_{2} \mathrm{O}_{2}$ toxicity after heat shock (Fig. 9, bottom panel).

Mechanism of heat-induced resistance to $\mathrm{H}_{2} \mathrm{O}_{2}$ : activation at the level of transcription. We hypothesized that the relative resistance of log-phase promastigotes to $\mathrm{H}_{2} \mathrm{O}_{2}$ after exposure to heat might be due to induction of a protective protein or proteins at the level of transcription, similar to the mechanism invoked for oxidant resistance factors in $E$. coli $(20,32)$. To investigate this possibility, we added the transcription inhibitor actinomycin D to promastigotes during their exposure to heat shock. The optimal actinomycin D concentration was first determined according to its ability to inhibit incorporation of $\left[{ }^{3} \mathrm{H}\right]$ uracil into TCA-precipitable promastigote RNA. The amount of $\left[{ }^{3} \mathrm{H}\right]$ uracil stably incorporated into RNA over $1 \mathrm{~h}$ was decreased from 91,977 to $16,185 \mathrm{dpm}$ with the inclusion of $1.0 \mu \mathrm{g}$ actinomycin $\mathrm{D} / \mathrm{ml}$ in cultures, and to $2,846 \mathrm{dpm}$ with the addition of $10 \mu \mathrm{g}$ actinomycin $\mathrm{D} / \mathrm{ml}$. Higher actinomycin D concentrations (up to $60 \mu \mathrm{g} / \mathrm{ml}$ ) did not further decrease the amount of labeled RNA.

Accordingly, $10 \mu \mathrm{g}$ actinomycin $\mathrm{D} / \mathrm{ml}$ or buffer was added to promastigotes in log-phase growth for $30 \mathrm{~min}$ before exposure to heat shock $\left(37^{\circ} \mathrm{C}, 2 \mathrm{~h}\right)$, and their susceptibility to $\mathrm{H}_{2} \mathrm{O}_{2}$

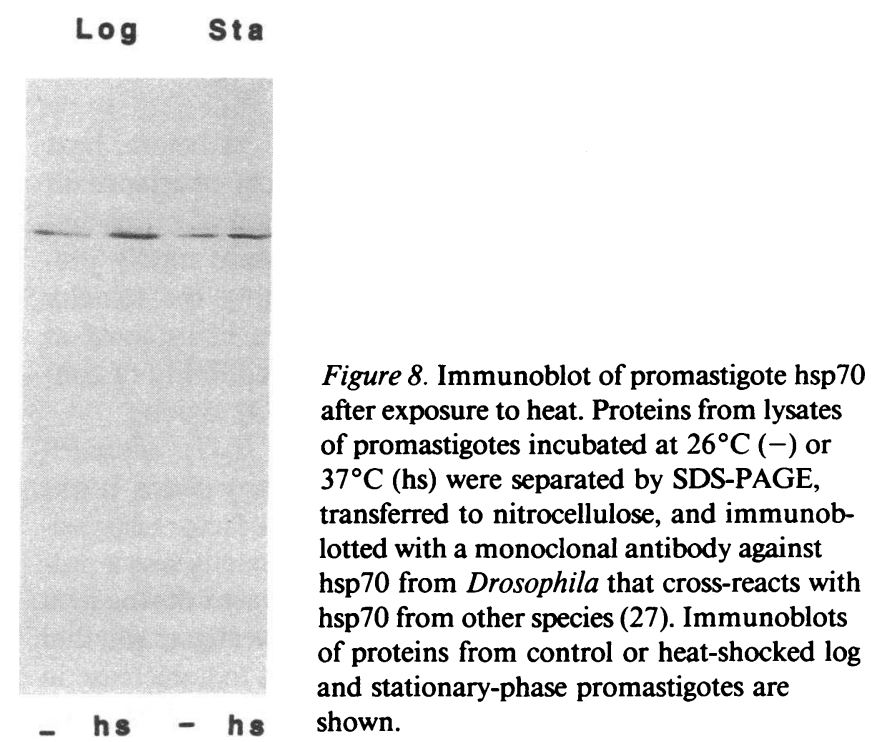

Figure 8. Immunoblot of promastigote hsp70 after exposure to heat. Proteins from lysates transferred to nitrocellulose, and immunoblotted with a monoclonal antibody against hsp70 from Drosophila that cross-reacts with hsp70 from other species (27). Immunoblots froteins from control or heat-shocked log and station. 
LOQ PHASE

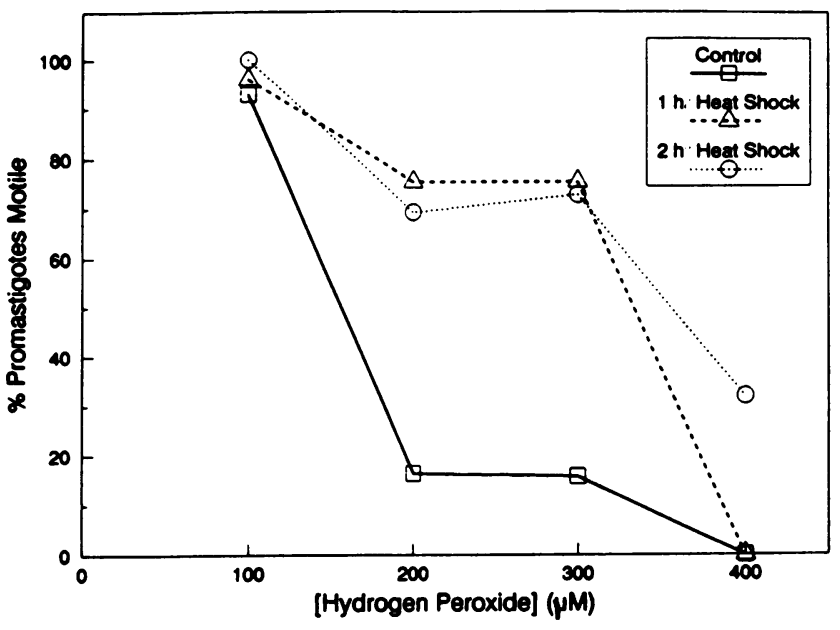

STATIONARY PHASE

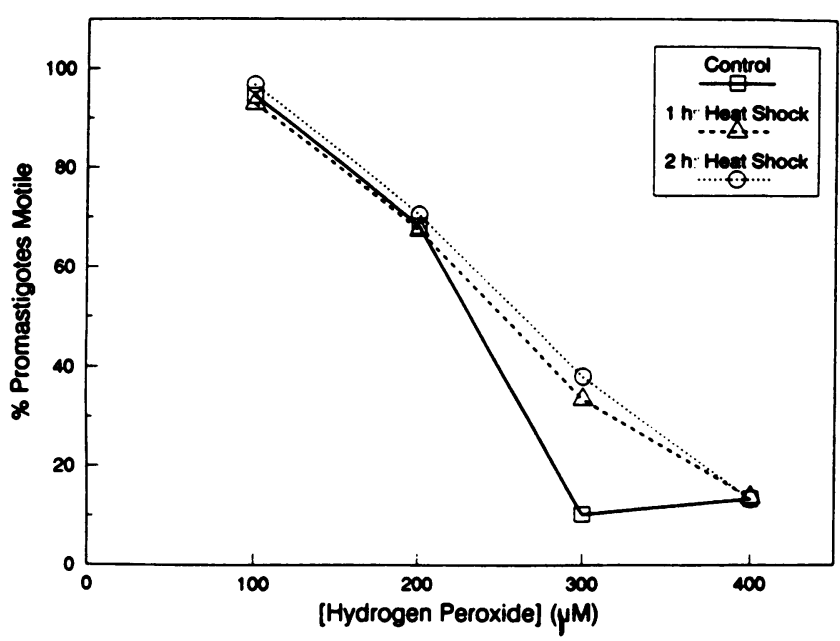

Figure 9. Effect of heat shock on toxicity of $\mathrm{H}_{2} \mathrm{O}_{2}$ for log- or stationary-phase promastigotes. Promastigotes were incubated in culture medium at $37^{\circ} \mathrm{C}$ for 1 or $2 \mathrm{~h}$ (heat shock), or at $26^{\circ} \mathrm{C}$ (control). They were then washed and exposed to $\mathrm{H}_{2} \mathrm{O}_{2}$ as above. Shown are representative $\mathrm{H}_{2} \mathrm{O}_{2}$ toxicity curves for log-phase (upper panel) or stationary-phase (lower panel) promastigotes with or without heat exposure.

toxicity was subsequently assessed (Fig. 10). As before, heat shock resulted in an increase in promastigote resistance to $\mathrm{H}_{2} \mathrm{O}_{2}$-mediated toxicity. However, the inclusion of actinomycin $\mathrm{D}$ with promastigotes during heat exposure totally prevented the development of resistance, shifting the toxicity curve down to the level of control parasites maintained at $26^{\circ} \mathrm{C}$. Actinomycin D did not effect the susceptibility of control promastigotes (incubated at $26^{\circ} \mathrm{C}$ ) to $\mathrm{H}_{2} \mathrm{O}_{2}$ toxicity.

Mechanism of heat-induced resistance to $\mathrm{H}_{2} \mathrm{O}_{2}$ : comparison to resistance induced by growth to stationary phase. It was evident from the above section that at least one factor responsible for the heat-induced resistance to $\mathrm{H}_{2} \mathrm{O}_{2}$ toxicity was a protein or proteins whose transcription was activated during heat shock. We performed EPR spectroscopy to investigate whether this increased resistance might be due in part to a decrease in the formation of $\cdot \mathrm{OH}$ from $\mathrm{H}_{2} \mathrm{O}_{2}$ after heat shock. Log-phase

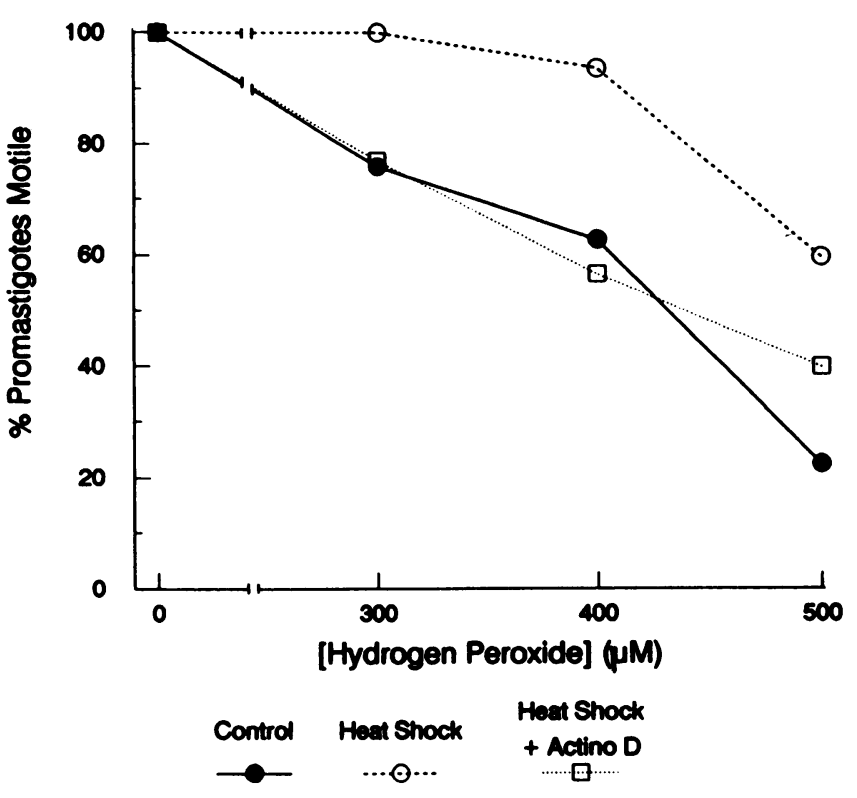

Figure 10. Effect of actinomycin D on heat-induced protection. Logphase promastigotes were exposed to $37^{\circ} \mathrm{C}$ heat shock for $2 \mathrm{~h}$ as in Fig. 9, with or without the inclusion of the transcription inhibitor actinomycin $\mathrm{D}$ in the cultures. Control promastigotes were incubated without actinomycin D at $26^{\circ} \mathrm{C}$ (control curve). Parasites were then washed and their susceptibility to $\mathrm{H}_{2} \mathrm{O}_{2}$ was assessed. Additional control promastigotes incubated at $26^{\circ} \mathrm{C}$ with actinomycin D had similar susceptibility to $\mathrm{H}_{2} \mathrm{O}_{2}$ as parasites in the control curve (not shown).

promastigotes were incubated in $\mathrm{HBSS}$ at $37^{\circ} \mathrm{C}$ (heat shock) or $26^{\circ} \mathrm{C}$ (control) for $2 \mathrm{~h} . \mathrm{H}_{2} \mathrm{O}_{2}$ was then added, and EPR spectroscopy was performed in the presence of DMPO and DMSO. A typical EPR spectrum indicating the formation of $\cdot \mathrm{OH}$ was seen with both heat shocked and control promastigotes (Figure 11). There was no apparent difference in the amount of $\cdot \mathrm{OH}$ formed in promastigotes with or without heat shock.

\section{Discussion}

Phagocytosis of Leishmania donovani promastigotes by human mononuclear phagocytes triggers an oxidative response which results in the generation of a number of toxic oxidant species, including superoxide and $\mathrm{H}_{2} \mathrm{O}_{2}(5-7,34)$. Despite the fact that promastigotes are readily killed in vitro upon exposure to $\mathrm{H}_{2} \mathrm{O}_{2}(12,30,35)$, a small percentage survive the oxidative burst and transform into amastigotes $(5,36)$. The factor(s) that allow some promastigotes to survive despite the local production of oxidant species have not yet been defined. The present study describes a correlation between increasing infectivity of L. $d$. chagasi promastigotes as they develop from log to stationary phase in liquid culture medium, and their relative resistance to the toxic effects of $\mathrm{H}_{2} \mathrm{O}_{2}$. A developmental increase in virulence has previously been documented in the case of $L$. major promastigotes as they progress from log to stationary phase, although a cause for this developmental increase has not yet been proven (13). Based on the data presented here we hypothesize that increased resistance to the toxic effects of $\mathrm{H}_{2} \mathrm{O}_{2}$ contributes to the in vitro development of virulence in $L$. d. chagasi. 


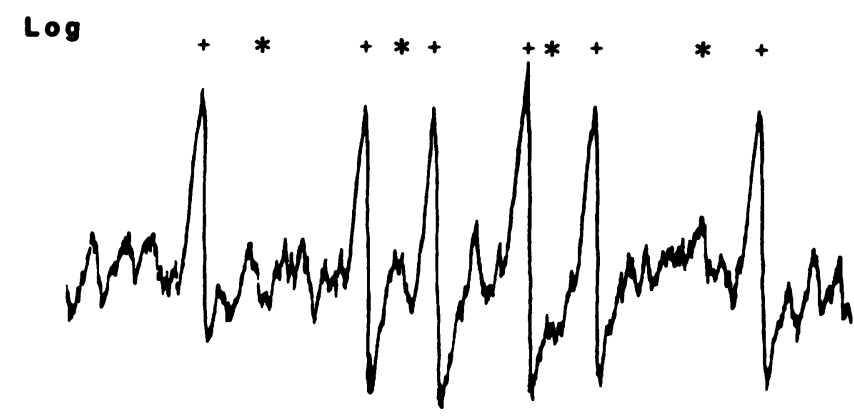

Log-Heat shock

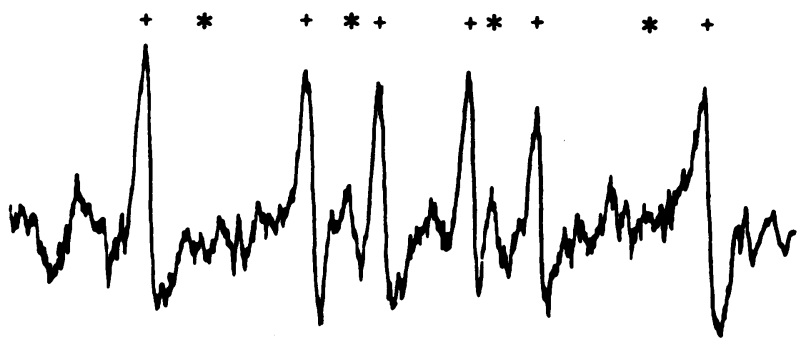

100

Figure 11. EPR spectra of heat shocked or control promastigotes 30 min after the addition of $\mathrm{H}_{2} \mathrm{O}_{2}$ to a solution of DMPO, DMSO, and DTPA containing $\log$ phase promastigotes incubated at $26^{\circ} \mathrm{C}(\log )$ or $37^{\circ} \mathrm{C}(\mathrm{Log}$-Heat Shock) for $2 \mathrm{~h}$. Spectral peaks corresponding to $\mathrm{DMPO} / \cdot \mathrm{CH}_{3}(+)$ and $\mathrm{DMPO} / \cdot \mathrm{OH}(*)$ are labeled.

Promastigotes also become less virulent (37) and more susceptible to $\mathrm{H}_{2} \mathrm{O}_{2}$ toxicity with increased length of cultivation in vitro. Similarly, Channon and Blackwell (30) found that recently isolated ("new") $L$. donovani promastigotes were more resistant to $\mathrm{H}_{2} \mathrm{O}_{2}$ than were multiply passaged ("old") promastigotes consistent with our findings, although their experiments were performed using exclusively log phase promastigotes (30). A comparison of Figs. 3 and 4 illustrates that there are wide variations in the susceptibility of different populations of $\log$ phase promastigotes to $\mathrm{H}_{2} \mathrm{O}_{2}$ toxicity. Factors contributing to these differences likely include the duration of maintenance in culture as described above, and the point at which the parasites are harvested during their transition from log to stationary phase. There also seem to be inherent differences between the susceptibility of promastigote populations isolated from different hamsters to $\mathrm{H}_{2} \mathrm{O}_{2}$ toxicity, probably reflecting differences in their expression of innate resistance factors. It may be that delineation of the latter differences will direct us toward identification of the mechanisms responsible for $\mathrm{H}_{2} \mathrm{O}_{2}$ resistance.

The actual mediator of $\mathrm{H}_{2} \mathrm{O}_{2}$ toxicity has not previously been established. By spin trapping we found that $\cdot \mathrm{OH}$ is generated in $L$. d. chagasi promastigotes after exposure to $\mathrm{H}_{2} \mathrm{O}_{2}$, and that chelation of promastigote iron with deferoxamine reversed both the toxic effects of $\mathrm{H}_{2} \mathrm{O}_{2}$ and the generation of $\cdot \mathrm{OH}$. Thus, $\mathrm{H}_{2} \mathrm{O}_{2}$ toxicity probably occurred through generation of - OH according to the Fenton reaction, catalyzed by endogenous stores of iron in promastigotes. Our studies with fractionated cells indicate that $\cdot \mathrm{OH}$ is formed in the cytosolic fraction of promastigotes. We have not further characterized the storage form and location of catalytically active iron, and indeed the mode of iron storage has not yet been documented in any Leishmania sp. In many other cell types, iron is stored bound to ferritin. In the presence of a reducing source, ferritin-bound iron has been shown to release its iron which in turn can react with $\mathrm{H}_{2} \mathrm{O}_{2}$ to generate $\cdot \mathrm{OH}$ (38). Many cells also contain insoluble iron chelates (hemosiderin) and a variety of low molecular weight iron chelates, each of which could potentially participate in the Fenton reaction. Finally, most cells also contain a number of cytosolic iron containing enzymes.

Murray found that $\mathrm{H}_{2} \mathrm{O}_{2}$ toxicity for $L$. donovani was prevented by the $\mathrm{H}_{2} \mathrm{O}_{2}$ scavenger catalase, whereas $\cdot \mathrm{OH}$ scavengers (mannitol, benzoate, diazabicyclooctane, and histidine) had no protective effect (12). In contrast, we found that mannitol partially protected $L$. $d$. chagasi promastigotes against the immobilizing effects of $\mathrm{H}_{2} \mathrm{O}_{2}$. Since $\cdot \mathrm{OH}$ was generated in the cytosolic but not the membrane fraction of log-phase promastigotes after the addition of $\mathrm{H}_{2} \mathrm{O}_{2}$, the partial protection afforded by mannitol may have occurred due to scavenging of intracellular $\cdot \mathrm{OH}$. The discrepancy between our results and Murray's could be explained if the two strains differed in their membrane permeability to mannitol, or in their intracellular content of catalytically active iron. Related to the latter possibility, our promastigote culture medium contained iron in the form of hemin whereas Murray's medium did not (12). Therefore the two strains may have varied markedly in their concentrations of intracellular iron available for $\cdot \mathrm{OH}$ generation.

Exposure of the more resistant stationary-phase promastigotes to $\mathrm{H}_{2} \mathrm{O}_{2}$ resulted in considerably lower magnitudes of - $\mathrm{OH}$ compared to the more $\mathrm{H}_{2} \mathrm{O}_{2}$-sensitive log-phase parasites. The decreased amount of $\cdot \mathrm{OH}$ observed with stationaryphase promastigotes could result either from increased removal (scavenging) of $\mathrm{H}_{2} \mathrm{O}_{2}$ and/or $\cdot \mathrm{OH}$, or to decreased amounts of catalytic iron in the more resistant form of the organism. The data presented here cannot definitively differentiate between these two possibilities. The major surface glycolipid lipophosphoglycan, which is known to scavenge oxidant species $(18,39,40)$, is probably not responsible for the decrease in $\cdot \mathrm{OH}$, since cytosolic fractions of log-phase promastigotes generated greater amounts of $\cdot \mathrm{OH}$ than cytosol from stationary-phase organisms. Channon and Blackwell (30) found that $L$. donovani promastigotes and amastigotes remove $\mathrm{H}_{2} \mathrm{O}_{2}$ from extracellular medium. Both Blackwell's and Murray's groups documented the presence of enzymatic antioxidants (catalase, glutathione reductase, glutathione peroxidase), although the data on which enzymes were present in the parasite's morphologic stages were not in exact agreement $(12,35,41)$. Blackwell also documented large quantities of total thiols in promastigote lysates, which can act as nonenzymatic scavengers of oxidants (35). Thus, it is likely that both enzymatic and nonenzymatic scavenging mechanisms participate in the increased resistance of stationary phase promastigotes to $\mathrm{H}_{2} \mathrm{O}_{2}$ toxicity. A candidate scavenger of oxidants in Leishmania is trypanothione, a conjugate of glutathione and spermidine that is unique to the Trypanosomatid protozoa. The redox state of trypanothione is maintained by the enzyme couple trypanothione reductase and (presumed) trypanothione peroxidase, similar to the glutathione reductase-glutathione peroxidase enzyme couple in other eukaryotes $(42,43)$. The identification of the enzymatic and nonenzymatic scavenging that develop during stationary phase may reveal important factors determining promastigote virulence. 
Eukaryotic and prokaryotic cells synthesize a set of highly conserved proteins termed heat shock proteins upon exposure to increased temperature, oxidative stress and other adverse environmental stimuli, and at different developmental stages. This heat shocked or "stressed" state is associated with an increased resistance against the toxic effects of heat or oxidants, sometimes resulting in an increase in virulence $(27,32,44-48)$. Leishmania sp. encounter a dramatic increase in ambient temperature when they are inoculated by the sandfly vector into a mammalian host. This exposure causes biochemical and morphologic changes that are associated with an increase in the production of several proteins including heat shock proteins. Some Leishmania sp. also transform to an amastigote-like form and increase their virulence characteristics after heat exposure $(19,49-52)$. In our hands incubation at $37^{\circ} \mathrm{C}$ constitutes a "heat shock" for $L$. d. chagasi, defined as an increase in the production of hsp70. Although hsp70 is probably not itself involved in protection against $\mathrm{H}_{2} \mathrm{O}_{2}$ toxicity, its increased expression may indicate the development of a "stressed" state that is also associated with increased resistance to $\mathrm{H}_{2} \mathrm{O}_{2}$. The reason for the relative inability of heat shock to induce $\mathrm{H}_{2} \mathrm{O}_{2}$ resistance of stationary phase promastigotes may reflect the fact that they were already in a partially "stressed" state. Consistent with this, promastigotes of $L$. major (53) and $L$. d. chagasi (our unpublished observations) express greater amounts of hsp70 mRNA as they develop from log to stationary phase. Furthermore, in contrast to the $\mathrm{H}_{2} \mathrm{O}_{2}$ resistance that developed during growth to stationary phase, heat shock of log-phase parasites was not associated with a decrease in the amount of $\cdot \mathrm{OH}$ produced after exposure to $\mathrm{H}_{2} \mathrm{O}_{2}$. It seems likely, therefore, that protection against $\mathrm{H}_{2} \mathrm{O}_{2}$ toxicity after heat shock of $\log$ phase promastigotes is related to either increased resistance to - OH-mediated injury or induction of cellular repair mechanisms.

Several factors beyond those addressed in this study contribute to the parasite's ability to survive macrophage-derived oxidant-mediated toxicity. Leishmania-infected murine macrophages have a diminished capacity to undergo an oxidative response, suggesting that parasites may partially inhibit their oxidative capacities (54). Relevant to this finding, promastigotes possess a soluble acid phosphatase that inhibits the production of superoxide by human neutrophils, and which could act in a similar fashion in macrophages (55). In addition, leishmania LPG has been reported to inhibit the activity of protein kinase $\mathrm{C}$ from rat brain and signal transduction in human monocytes, and it is hypothesized that this might decrease the respiratory burst upon phagocytosis by macrophages $(56,57)$. Finally, using mononuclear phagocytes from patients with chronic granulomatous disease, that are defective in their capacity to generate oxidants, Murray showed that both oxygendependent and oxygen-independent mechanisms contribute to the killing of leishmania within the macrophage (34). The respiratory burst that is stimulated upon phagocytosis of promastigotes by macrophages may be important in promastigote killing during the early phases of infection, but killing of intracellular amastigotes throughout disease probably requires activation of macrophage by cytokines such as interferon- $\gamma$ $(58,59)$. Oxygen-independent mechanisms relevant to the latter aspect of intracellular killing include the L-arginine-derived product nitric oxide. Nitric oxide participates in killing of $L$. major promastigotes during phagocytosis by activated murine macrophages, as well as interferon- $\gamma$-mediated activation of murine macrophages to kill intracellular $L$. major amastigotes $(60,61)$. However, production of nitric oxide by human macrophages has not been clearly demonstrated (62), leaving at issue the role of this oxidant species in human leishmaniasis. Furthermore, a role for nitric oxide in killing promastigotes by resting macrophages, as occurs during initial infection of a naive host, has not been documented in any species. It seems likely that evasion of $\mathrm{H}_{2} \mathrm{O}_{2}$ toxicity may be critical for the survival of promastigotes during this initial step. Thus the means by which promastigotes resist $\mathrm{H}_{2} \mathrm{O}_{2}$ toxicity, which occurs by at least two mechanisms according to the above data, may be an important determinant of the virulence of $L$. $d$. chagasi promastigotes.

\section{Acknowledgments}

We are grateful to Kurt Andersen and Tedmund Roeder for their laboratory skills, and to Naomi Erickson and Kathy Schmuecker for their help with preparation of this manuscript.

This work was supported in part by Veterans Administration Merit Review Grants to Dr. Wilson and Dr. Britigan, by Physician Scientist Award AI-00832 from the NIH (Dr. Wilson), and National Institutes of Health grants AI28412 and HL44275 (both to Dr. Britigan). It was performed during the tenure of Dr. Britigan as a Veterans Administration Research Associate and a Pfizer Scholar.

\section{References}

1. Pearson, R. D., D. A. Wheeler, L. H. Harrison, and H. D. Kay. 1983. The immunobiology of leishmaniasis. Rev. Infect. Dis. 5:907-926.

2. Russell, D. G., and P. Talamas-Rohana. 1989. Leishmania and the macrophage: a marriage of inconvenience. Immunol. Today. 10:328-333.

3. Blackwell, J. M., R. A. B. Ezekowitz, M. B. Roberts, J. Y. Channon, R. B. Sim, and S. Gordon. 1985. Macrophage complement and lectin-like receptors bind Leishmania in the absence of serum. J. Exp. Med. 162:324-331.

4. Wilson, M. E., and R. D. Pearson. 1988. Roles of CR3 and mannose receptors in the attachment and ingestion of Leishmania donovani by human mononuclear phagocytes. Infect. Immun. 56:363-369.

5. Pearson, R. D., J. L. Harcus, P. H. Symes, R. Romito, and G. R. Donowitz. 1982. Failure of the phagocytic oxidative response to protect human monocytederived macrophages from infection by Leishmania donovani. J. Immunol. 129:1282-1286

6. Murray, H. W. 1981. Interaction of Leishmania with a macrophage cell line. Correlation between intracellular killing and the generation of oxygen intermediates. J. Exp. Med. 153:1690-1695.

7. Murray, H. W. 1986. Cellular resistance to protozoal infection. Annu. Rev. Med. 37:61-69.

8. Johnston, W. D., Jr., B. Mei, and Z. A. Cohn. 1977. The separation, longterm cultivation, and maturation of the human monocyte. J. Exp. Med. 146:1613-1626.

9. Imlay, J. A., and S. Linn. 1988. DNA damage and oxygen radical toxicity. Science (Wash. DC). 240:1302-1309.

10. Repine, J. E., R. B. Fox, and E. M. Berger. 1981. Hydrogen peroxide kills Staphylococcus aureus by reacting with staphylococcal iron to form hydroxyl radical. J. Biol. Chem. 256:7094-7096.

11. Weiss, S. J. 1986. Oxygen, ischemia, and inflammation. Acta Psychiatr Scand. Suppl. 548:9-37.

12. Murray, H. W. 1981. Susceptibility of Leishmania to oxygen intermediates and killing by normal macrophages. J. Exp. Med. 153:1302-1315.

13. Sacks, D. L., and P. V. Perkins. 1984. Identification of an infective stage of Leishmania promastigotes. Science (Wash. DC). 223:1417-1419.

14. da Silva, R., and D. L. Sacks. 1987. Metacyclogenesis is a major determinant of Leishmania promastigote virulence and attenuation. Infect. Immun. 55:2802-2806.

15. Kweider, M., J.-L. Lemesre, F. Darcy, J.-P. Kusnierz, A. Capron, and F. Santoro. 1987. Infectivity of Leishmania braziliensis promastigotes is dependent on the increasing expression of a 65,000 -dalton surface antigen. J. Immunol. 138:299-305.

16. Wilson, M. E., K. E. Paetz, M. Maybodi, and J. E. Donelson. 1990 Expression of gp63 by log or stationary phase Leishmania donovani chagasi (Ldc) promastigotes. FASEB (Fed. Am. Soc. Exp. Biol.) J. 4:A2190. (Abstr.)

17. Sacks, D. L., and R. P. DaSilva. 1987. The generation of infective stage Leishmania major promastigotes is associated with the cell-surface expression and release of a developmentally regulated glycolipid. J. Immunol. 139:30993106. 
18. Sacks, D. L., T. N. Brodin, and S. J. Turco. 1990. Developmental modification of the lipophosphoglycan from Leishmania major promastigotes during metacyclogenesis. Mol. Biochem. Parasitol. 42:225-234.

19. Searle, S. A., A. J. R. Campos, R. M. R. Coulson, T. W. Spithill, and D. F Smith. 1989. A family of heat shock protein 70-related genes are expressed in the promastigotes of Leishmania major. Nucleic Acids Res. 17:5081-5095.

20. Jenkins, D. E., J. E. Schultz, and A. Matin. 1988. Starvation-induced cross protection against heat or $\mathrm{H}_{2} \mathrm{O}_{2}$ challenge in Escherichia coli. J. Bacteriol. 170:3910-3914.

21. Wilson, M. E., and R. D. Pearson. 1986. Evidence that Leishmania donovani utilizes a mannose receptor on human mononuclear phagocytes to establish intracellular parasitism. J. Immunol. 136:4681-4688.

22. Pearson, R. D., and R. T. Steigbigel. 1980. Mechanism of lethal effect of human serum upon Leishmania donovani. J. Immunol. 125:2195-2201.

23. Stauber, L. A. 1958. Host resistance to the Khartoum strain of Leish mania donovani. Rice Inst. Pamphlets. 45:80-96.

24. Dixit, V. M., S. Green, V. Sarma, L. B. Holzman, F. W. Wolf, K O'Rourke, P. A. Ward, E. V. Prochownik, and R. M. Marks. 1990. Tumor necrosis factor- $\alpha$ induction of novel gene products in human endothelial cells including a macrophage-specific chemotaxin. J. Biol. Chem. 265:2973-2978.

25. Kelly, K., B. H. Cochran, C. D. Stiles, and P. Leder. 1983. Cell-specific regulation of the c-myc gene by lymphocyte mitogens and platelet-derived growth factor. Cell. 35:603-610.

26. Laemmli, U. K. 1970. Cleavage of structural proteins during the assembly of the head of bacteriophage T4. Nature (Lond.). 227:680-685.

27. Kurtz, S. J., J. Rossi, L. Petko, and S. Lindquist. 1986. An ancient developmental induction: Heat-shock proteins induced in sporulation and oogenesis Science (Wash. DC). 231:1154-1157.

28. Wilson, M. E., and K. K. Hardin. 1988. The major concanavalin A-binding surface glycoprotein of Leishmania donovani chagasi promastigotes is involved in attachment to human macrophages. J. Immunol. 141:265-272.

29. Britigan, B. E., G. M. Rosen, Y. Chai, and M. S. Cohen. 1986. Do human neutrophils make hydroxyl radical? Determination of free radicals generated by human neutrophils activated with a soluble or particulate stimulus using electron paramagnetic resonance spectrometry. J. Biol. Chem. 261:4426-4431.

30. Channon, J. Y., and J. M. Blackwell. 1985. A study of the sensitivity of Leishmania donovani promastigotes and amastigotes to hydrogen peroxide. I. Differences in sensitivity correlate with parasite-mediated removal of hydrogen peroxide. Parasitology. 91:197-206.

31. Rosen, G. M., and E. Finkelstein. 1985. Use of spin traps in biological systems. Adv. Free Radical Biol. Med. 1:345-375.

32. Greenberg, J. T., and B. Demple. 1989. A global response induced in Escherichia coli by redox-cycling agents overlaps with that induced by peroxide stress. J. Bacteriol. 171:3933-3939.

33. Polla, B. S. 1988. A role for heat shock proteins in inflammation? Immunol. Today. 9:134-137.

34. Murray, H. W., and D. M. Cartelli. 1983. Killing of intracellular Leishmania donovani by human mononuclear phagocytes. J. Clin. Invest. 72:32-44.

35. Channon, J. Y., and J. M. Blackwell. 1985. A study of the sensitivity of Leishmania donovani promastigotes and amastigotes to hydrogen peroxide. II. Possible mechanisms involved in protective $\mathrm{H}_{2} \mathrm{O}_{2}$ scavenging. Parasitology. 91:207-217.

36. Pearson, R. D., J. L. Harcus, D. Roberts, and G. R. Donowitz. 1983 Differential survival of Leishmania donovani amastigotes in human monocytes. J. Immunol. 131:1994-1999.

37. Wilson, M. E., K. K. Hardin, and J. E. Donelson. 1989. Expression of the major surface glycoprotein of Leishmania donovani chagasi in virulent and attenuated promastigotes. J. Immunol. 143:678-684.

38. Halliwell, B., and J. M. Gutteridge. 1986. Oxygen free radicals and iron in relation to biology and medicine: Some problems and concepts. Arch. Biochem. Biophys. 246:501-514.

39. Chan, J., T. Fujiwara, P. Brennan, M. McNeil, S. J. Turco, J. C. Sibille, M Snapper, P. Aisen, and B. R. Bloom. 1989. Possible virulence factors that scavenge oxygen radicals. Proc. Natl. Acad. Sci. USA. 86:2453-2457.

40. Wack, M. F., J. E. Donelson, B. E. Britigan, and M. E. Wilson. 1990. Variation of lipophosphoglycan (LPG) on virulent and avirulent forms of Leishmania donovani chagasi. FASEB (Fed. Am. Soc. Exp. Biol.) J. 4:A2191 (Abstr.).
41. Murray, H. W. 1982. Cell-mediated immune response in experimental visceral leishmaniasis. II. Oxygen-dependent killing of intracellular Leishmania donovani amastigotes. J. Immunol. 129:351-357.

42. Jockers-Scherubl, M. C., R. H. Schirmer, and R. L. Krauth-Siegel. 1989. Trypanothione reductase from Trypanosoma cruzi. Catalytic properties of the enzyme and inhibition studies with trypanocidal compounds. Eur. J. Biochem. 180:267-272.

43. Fairlamb, A. H., G. B. Henderson, and A. Cerami. 1989. Trypanothione is the primary target for arsenical drugs against African trypanosomes. Proc. Natl. Acad. Sci. USA. 86:2607-2611.

44. Lindquist, S. 1986. The heat-shock response. Annu. Rev. Biochem. 55:1151-1191.

45. Buchmeier, N. A., and F. Heffron. 1990. Induction of Salmonella stress proteins upon infection of macrophages. Science (Wash. DC). 248:730-732.

46. Pelham, H. R. B. 1986. Speculations on the functions of the major heat shock and glucose-regulated proteins. Cell. 46:959-961.

47. Bienz, M. 1985. Transient and developmental activation of heat-shock genes. Trends Biochem. Sci. (April):157-161.

48. Lathigra, R. B., P. D. Butcher, and D. B. Young. 1991. Heat shock proteins as virulence factors of pathogens. Curr. Top. Microbiol. Immunol. 167:125143.

49. Smejkal, R. M., R. Wolff, and J. G. Olenick. 1988. Leishmania braziliensis panamensis: increased infectivity resulting from heat shock. Exp. Parasitol. 65:1-9.

50. Shapira, M., J. G. McEwen, and C. L. Jaffe. 1988. Temperature effects on molecular processes which lead to stage differentiation in Leishmania. EMBO (Eur. Mol. Biol. Organ.). J. 7:2895-2901.

51. VanderPloeg, L. H. T., S. H. Giannini, and C. R. Cantor. 1985. Heat shock genes: Regulatory role for differentiation in parasitic protozoa. Science (Wash. DC.) 228:1443-1446.

52. Lawrence, F., and M. Robert-Gero. 1985. Induction of heat shock and stress proteins in promastigotes of three Leishmania species. Proc. Natl. Acad. Sci. USA. 82:4414-4417.

53. Lee, M. G. S., B. L. Atkinson, S. H. Giannini, and L. H. T. VanderPloeg. 1988. Structure and expression of hsp 70 gene family of Leishmania major. Nucleic Acids Res. 16:9567-9585.

54. Buchmuller-Rouiller, Y., and J. Mauel. 1987. Impairment of the oxidative metabolism of mouse peritoneal macrophages by intracellular Leishmania spp. Infect. Immun. 55:587-591.

55. Remaley, A. T., D. B. Kuhns, R. E. Basford, R. H. Glew, and S. S. Kaplan. 1984. Leishmanial phosphatase blocks neutrophil O2-production. J. Biol. Chem. 259:11173-11175.

56. McNeely, T. B., and S. J. Turco. 1987. Inhibition of protein kinase C activity by the Leishmania donovani lipophosphoglycan. Biochem. Biophys. Res. Commun. 148:653-657.

57. Descoteaux, A., S. J. Turco, D. L. Sacks, and G. Matlashewski. 1991. Leishmania donovani lipophosphoglycan selectively inhibits signal transduction in macrophages. J. Immunol. 146:2747-2753.

58. Buchmuller, Y., and J. Mauel. 1981. Studies on the mechanisms of macrophage activation: Possible involvement of oxygen metabolities in killing of Leishmania enriettii by activated mouse macrophages. J. Reticuloendothel. Soc. 29:181-192.

59. Mauel, J., and Y. Buchmuller-Rouiller. 1987. Effect of lipopolysaccharide on intracellular killing of Leishmania enriettii and correlation with macrophage oxidative metabolism. Eur. J. Immunol. 17:203-208.

60. Green, S. J., M. S. Meltzer, Jr., J. B. Hibbs, and C. A. Nacy. 1990. Activated macrophages destroy intracellular Leishmania major amastigotes by an L-arginine-dependent killing mechanism. J. Immunol. 144:278-283.

61. Liew, F. Y., S. Millott, C. Parkinson, R. M. J. Palmer, and S. Moncada 1990. Macrophage killing of Leishmania parasite in vivo is mediated by nitric oxide from L-arginine. J. Immunol. 144:4794-4797.

62. Cameron, M. L., D. L. Granger, J. B. Weinberg, W. J. Kozumbo, and H. S. Koren. 1990. Human alveolar and peritoneal macrophages mediate fungistasis independently of $\mathrm{L}$-arginine oxidation to nitrite or nitrate. Am. Rev. Respir. Dis. 142:1313-1319. 